\title{
Cu Nanoparticle Array-Mediated III-V/Si Integration: Application in Series-Connected Tandem Solar Cells
}

Hidenori Mizuno, ${ }^{1, *}$ Kikuo Makita, ${ }^{2}$ Toshimitsu Mochizuki, ${ }^{1}$ Takeshi Tayagaki, ${ }^{2}$ Takeyoshi Sugaya, ${ }^{2}$ and Hidetaka Takato ${ }^{1}$

${ }^{1}$ Renewable Energy Research Center, Fukushima Renewable Energy Institute, National Institute of Advanced Industrial Science and Technology, 2-2-9 Machiike-dai, Koriyama, Fukushima 963-0298, Japan

${ }^{2}$ Research Center for Photovoltaic Technologies, National Institute of Advanced Industrial Science and Technology, Central 2, 1-1-1 Umezono, Tsukuba, Ibaraki 305-8568, Japan

*Corresponding Author, E-mail: h-mizuno@aist.go.jp

\section{Experimental Methods}

\section{Materials}

Polystyrene-block-poly-2-vinylpyridine (PS- $b$-P2VP) with the molecular weights of 133 and $132 \mathrm{~kg} / \mathrm{mol}$ (for PS and P2VP, respectively, PDI = 1.15) was purchased from Polymer Source, Inc. O-Xylene $(\geq 99.0 \%)$ was purchased from Sigma-Aldrich. $\mathrm{Na}_{2} \mathrm{PdCl}_{4} \cdot 3 \mathrm{H}_{2} \mathrm{O}$ (99\%) was purchased from Strem Chemicals. $\quad \mathrm{CuCl}_{2} \cdot 2 \mathrm{H}_{2} \mathrm{O}$ (Guaranteed grade) was purchased from FUJIFILM Wako Pure Chemical Corporation. GaAs single-junction top subcells (thickness: $2 \mu \mathrm{m}$ ) on GaAs wafers were purchased from LandMark Optoelectronics Corp., and InGaP/GaAs double-junction top subcells $(0.35 \mu \mathrm{m} / 0.6$ $\mu \mathrm{m}$ ) on GaAs wafers were fabricated following the procedure reported previously. ${ }^{1}$ Front electrodes were formed on these top subcells by electron beam evaporation of $\mathrm{Ni} / \mathrm{Ge} / \mathrm{Au}$ followed by rapid thermal annealing. Crystalline Si (c-Si) bottom subcells were fabricated using p-type (B-doped, resistivity $\left.=0.5-4 \Omega-\mathrm{cm}^{2}\right) \mathrm{Si}(100)$ wafers. The $\mathrm{n}^{+}-$Si front layer was formed by thermal diffusion of $\mathrm{POCl}_{3}$, and the $\mathrm{p}^{+}$-Si back surface field (BSF) layer and rear electrode were formed by screen printing of Al paste followed by firing. Typical sizes of the top and bottom subcells were $4 \mathrm{~mm} \times 4 \mathrm{~mm}$ and 8 $\mathrm{mm} \times 8 \mathrm{~mm}$, respectively.

\section{Fabrication of a Pd NP or Cu NR array on a c-Si subcell by Method A}

PS- $b$-P2VP was mixed with $o$-xylene and stirred for $1 \mathrm{~h}$ at $70{ }^{\circ} \mathrm{C}$ to make a $0.3 \mathrm{wt} \%$ solution. The solution was allowed to sit for $>24 \mathrm{~h}$ prior to use to complete the self-assembled micelle formation. This PS- $b$-P2VP micelle solution was spin-coated on a front surface of a c-Si subcell at $6000 \mathrm{rpm}$ for 40 s. The PS- $b$-P2VP-coated $c$-Si subcell was then drop-casted with $5 \mathrm{mM}$ aq. $\mathrm{Na}_{2} \mathrm{PdCl}_{4} \cdot 3 \mathrm{H}_{2} \mathrm{O}$ or $\mathrm{CuCl}_{2} \cdot 2 \mathrm{H}_{2} \mathrm{O}$ for $2 \mathrm{~min}$, rinsed thoroughly with a copious amount of water, and dried with a stream of nitrogen. Finally, the PS- $b-\mathrm{P} 2 \mathrm{VP}-\mathrm{Pd}^{2+}$ or $\mathrm{Cu}^{2+}$ coated c-Si subcell was treated with $\mathrm{Ar} / \mathrm{H}_{2}$ (3\%) plasma (Diener electronic Femto) at $0.4 \mathrm{mbar}\left(\mathrm{Ar} / \mathrm{H}_{2}\right.$ flow rate $=9 \mathrm{sccm}$ ) and $75 \mathrm{~W}$ for 3 min to form a Pd NP or Cu NR array and to remove the PS- $b$-P2VP template.

\section{Fabrication of a Cu NP array on a c-Si subcell by Method B}

$\mathrm{CuCl}_{2} \cdot 2 \mathrm{H}_{2} \mathrm{O}(10 \mathrm{mg})$ was mixed with a $0.3 \mathrm{wt} \%$-xylene solution of the PS- $b$-P2VP micelles $(4 \mathrm{~mL})$ and stirred for $120 \mathrm{~h}$ at $70^{\circ} \mathrm{C}$. The resulting solution was cooled to room temperature and filtered with a $0.2 \mu \mathrm{m}$ polytetrafluoroethylene (PTFE) syringe filter. This $\mathrm{Cu}^{2+}$-loaded PS- $b$-P2VP micelle solution was spin-coated on a front surface of a c-Si subcell at $6000 \mathrm{rpm}$ for $40 \mathrm{~s}$. The PS- $b-\mathrm{P} 2 \mathrm{VP}-\mathrm{Cu}^{2+} \mathrm{coated}^{2}$ 
c-Si subcell was treated with $\mathrm{Ar} / \mathrm{H}_{2}$ (3\%) plasma (Diener electronic Femto) at $0.4 \mathrm{mbar}\left(\mathrm{Ar} / \mathrm{H}_{2}\right.$ flow rate $=9 \mathrm{sccm}$ ) and $75 \mathrm{~W}$ for $3 \mathrm{~min}$ to form a Pd NP or Cu NR array and to remove the PS- $b$-P2VP template.

\section{Epitaxial lift-off (ELO) of a top subcell from a GaAs wafer}

The front surface of a III-V (GaAs or InGaP/GaAs) top subcell grown on a GaAs wafer was drop-coated with Apiezon Wax W. ${ }^{2}$ This sample was placed in a homemade PTFE container equipped with a sapphire cover. The container was immersed in $20 \%$ aq. HF for $\sim 7 \mathrm{~h}$ to release the III-V top subcell from the parent GaAs wafer as a thin-film. Subsequently, the container was carefully transferred into a beaker flowing with fresh water to wash the thin-film top subcell. After the water flow was stopped ( $10 \mathrm{~min}$ ), the container was transferred into a beaker filled with $\mathrm{EtOH}$.

\section{Fabrication of a III-V//Si smart stack tandem cell}

A metal (Pd NP, Cu NR, or Cu NP array)-decorated c-Si subcell was immersed in ETOH where an ELO thin-film top subcell was floating. The top subcell was scooped-up by the metal-decorated c-Si subcell from the EtOH using tweezers. After the excess EtOH was removed on a filter paper, the pre-stacked sample was pressed $(5 \mathrm{~N})$ using a custom-made press equipment and heated to $60^{\circ} \mathrm{C}$ for $20 \mathrm{~min}$. After the pressing was released, the Apiezon wax coating was removed by toluene, and the extra $n^{+}$-GaAs cap layer (not contacted with the AuGeNi front electrode) was etched away using a mixed solution of $\mathrm{NH}_{4} \mathrm{OH}$ and $\mathrm{H}_{2} \mathrm{O}_{2}$. In case of the InGaP/GaAs//Si cell, $\mathrm{TiO}_{2}(70 \mathrm{~nm})$ and $\mathrm{SiO}_{2}(100$ $\mathrm{nm}$ ) were sequentially deposited by sputtering to form an anti-reflection layer.

\section{Characterization}

Atomic force microscopy (AFM) was performed with Hitachi AFM5500M (dynamic force mode) using Si-based, backside Al-coated cantilevers whose spring constant is $42 \mathrm{~N} / \mathrm{m}$ (SI-DF40, Hitach High-Tech Science Corporation). Scanning electron microscopy (SEM) was performed with Hitachi SU8200 using an accelerating voltage of $3.0 \mathrm{kV}$. The image was taken under the secondary electron imaging mode. High-angle annular dark-field scanning transmission electron microscopy (HAADF-STEM) and energy dispersed X-ray spectroscopy (EDX) were performed with JEOL JEM-ARM200F and JED-2300T using an accelerating voltage of $200 \mathrm{kV}$. Photovoltaic current density-voltage $(J-V)$ characteristics were measured using SAN-EI Electric XHS-80S1 two-light source (Xenon-halogen) and ADCMT 6241A $\mathrm{DC}$ voltage current source/monitor system. The intensity of the light was calibrated using a c-Si reference cell (Konica Minolta, AK-200). The voltage was swept from -0.5 to $2.0 \mathrm{~V}$ for GaAs//Si cells and -0.5 to $3.2 \mathrm{~V}$ for InGaP/GaAs//Si cells with the step of $0.02 \mathrm{~V}$ and scan speed of $0.5 \mathrm{~V} / \mathrm{s}$. External quantum efficiency (EQE) measurements were carried out using Bunkoukeiki CEP-25ML-based system. For the $J-V$ characteristics and EQE measurements, aperture masks were applied to the cells to define the illumination area $\left(0.05098 \mathrm{~cm}^{2}\right.$ for GaAs//Si cells and $0.1475 \mathrm{~cm}^{2}$ for InGaP/GaAs//Si cells). Therefore, the reported characteristics in the main text were referred to as aperture area measurements, which include the shaded area by the front electrode of the smart stack cells.

\section{References}

[1] Sugaya, T.; Makita, K.; Takeda, A.; Oshima, R.; Matsubara, K.; Okano, Y.; Niki, S. Jpn. J. Appl. Phys. 2014, 53, 05FV06.

[2] Yablonovitch, E.; Hwang, D. M.; Gmitter, T. J.; Florez, L. T.; Harbison, J. P. Appl. Phys. Lett. 1990, 56, 2419. 


\section{Formation of $\mathrm{Cu}$ precipitates by galvanic displacement}

When the Cu nanoring (NR) array was fabricated on a native oxide-removed c-Si surface by Method A, formation of undesired micron-scale Cu-based precipitates shown in Figure S1 was frequently observed. As a result, smart stack of a top subcell was unable to be performed.

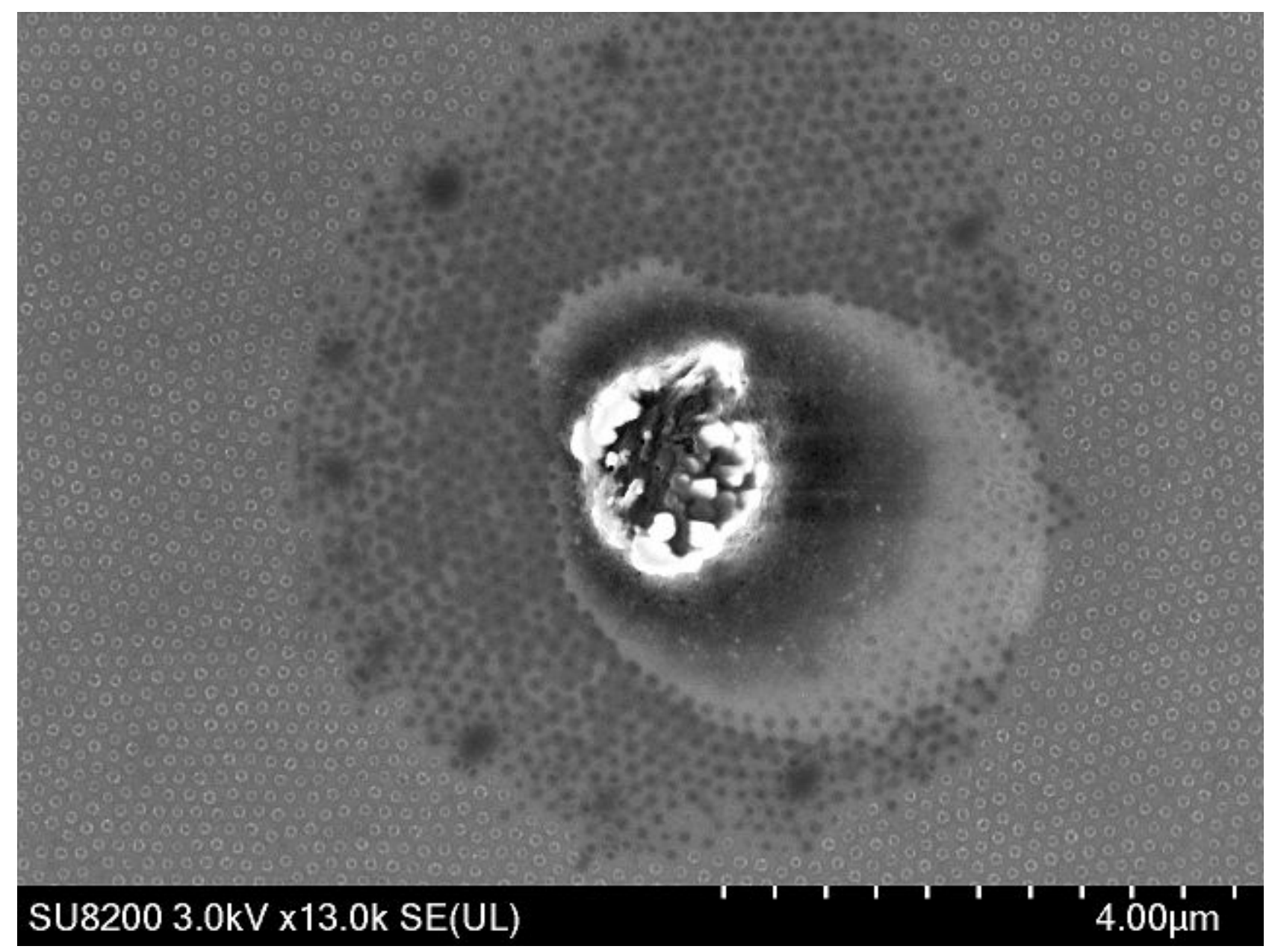

Figure S1. SEM image of a Cu precipitate formed when Method A was carried out on a native oxide-removed c-Si surface. 


\section{J-V characteristics of standard c-Si cells}

We have an ability to produce Al-back surface field (BSF) type c-Si cells with the performance shown below.

a)

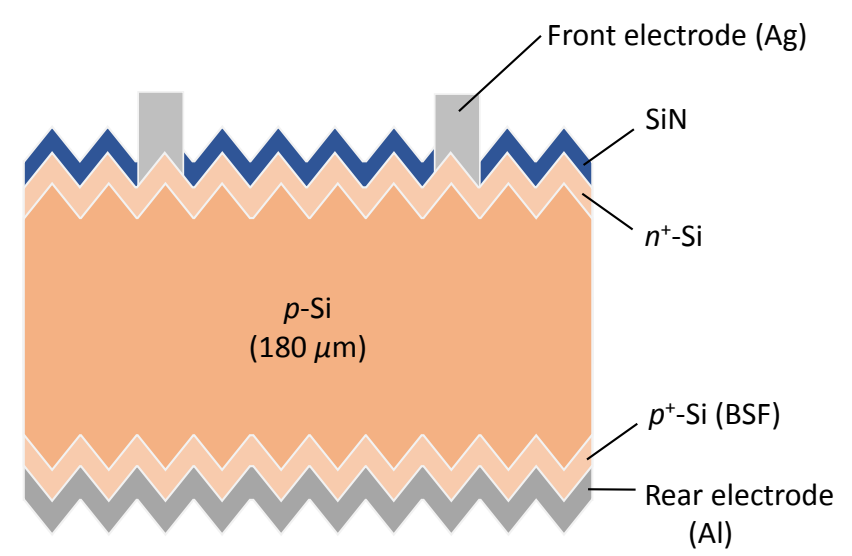

b)

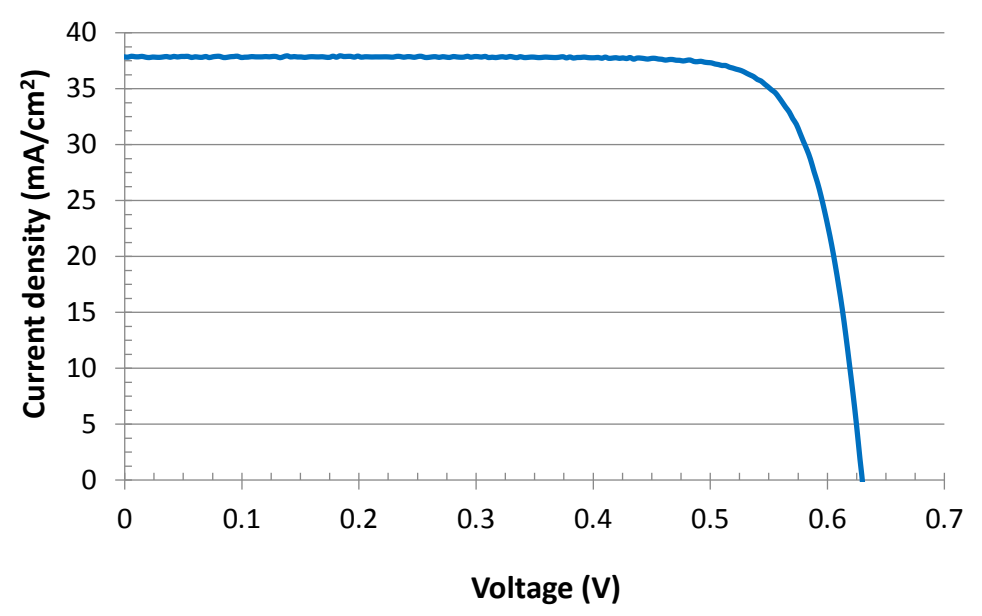

Figure S2. (a) Schematic of an Al-BSF type c-Si cell. $\quad$ (b) Typical J-V characteristics of the Al-BSF type c-Si cell, with a short circuit current density of $37.84 \mathrm{~mA} / \mathrm{cm}^{2}$, open circuit voltage of $0.630 \mathrm{~V}$, fill factor of 0.814 , and conversion efficiency of $19.4 \%$. 


\section{Details of Optical Simulation}

In order to estimate the effect of the Cu NP array on the absorption by each subcell, rigorous coupled wave analysis (RCWA) simulation was carried out using DiffractMOD, a commercially available software from Synopsis. Two simplified three-dimensional structures shown in Figure S3 were modeled. One (Model A) is for the smart stack cell which has an perfectly hexagonal Cu NP array at the GaAs/c-Si interface with the particle size (diameter) of $40 \mathrm{~nm}$, interparticle (center-to-center) distance of $155 \mathrm{~nm}$, and the thickness (i.e., the gap between the GaAs and c-Si layers) of $10 \mathrm{~nm}$. The other (Model B) is for comparison, where the GaAs and c-Si layers are connected directly. The thicknesses of top InGaP/GaAs were 350/600 nm, which were the same as those used in the actual smart stack cell. However, the thickness of the bottom c-Si (400 $\mu \mathrm{m})$ was set to be larger than the one used in the actual smart stack cell $(260 \mu \mathrm{m})$. This is to simplify the simulation by compensating for the rear texturing (light trapping) effect of the actual c-Si subcell. The optical constants of $\mathrm{Cu}, \operatorname{InGaP}, \mathrm{GaAs}$, and Si were obtained from Diffract MOD's database, [3], [4] with linear interpolation, and [5], respectively.

The size of one simulation unit in the $x-y$ plane was set to be $155 \mathrm{~nm} \times 268 \mathrm{~nm}$, and the periodic boundary conditions were applied among the simulation units. In the calculation of Model A, harmonics up to the ninth order for two axes parallel to the plane were considered.

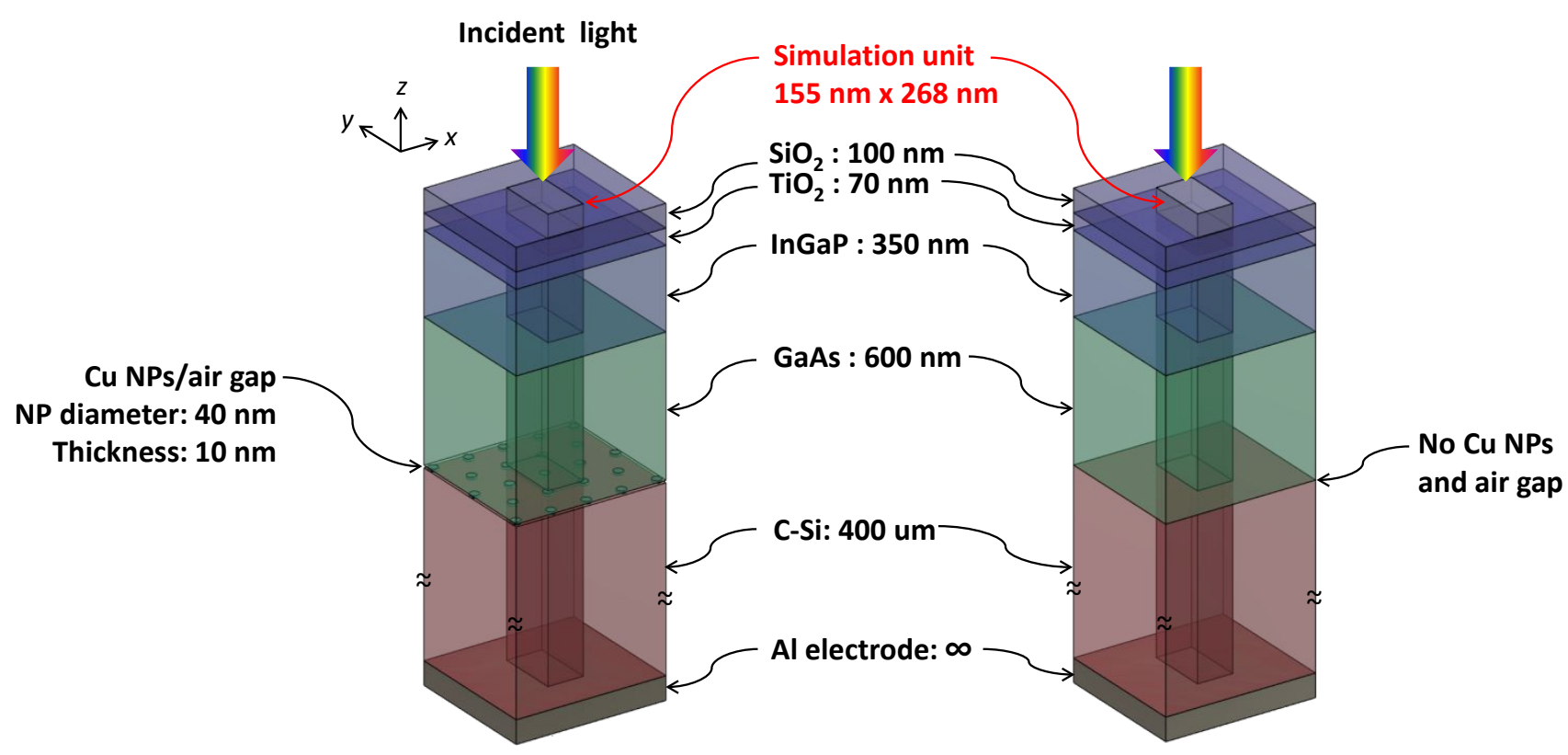

Model A

Model B

Figure S3. RCWA simulation model used in this study. 
Figure S4 shows the results of the simulation. A clear difference can be seen especially with the c-Si parts (orange plots). Compared to Model B (dotted orange plot), Model A (solid orange plot) showed remarkable interference due to the $10 \mathrm{~nm}$ of air gap at the GaAs/c-Si interface, which resulted in the reduced absorption around $880-1040 \mathrm{~nm}$. After $1040 \mathrm{~nm}$, slightly less absorption still continued, which overlapped well with the absorption by the Cu NPs (solid yellow plot). The degree of reduced absorption of Model A was calculated by integrating the absorptance in the 500-1200 nm wavelength range and taking the ratio of Model A/Model B. It turned out that the ratio was 0.947; therefore, the absorption loss of Model A (the c-Si part of the smart stack cell) could be estimated to be $5.3 \%$.

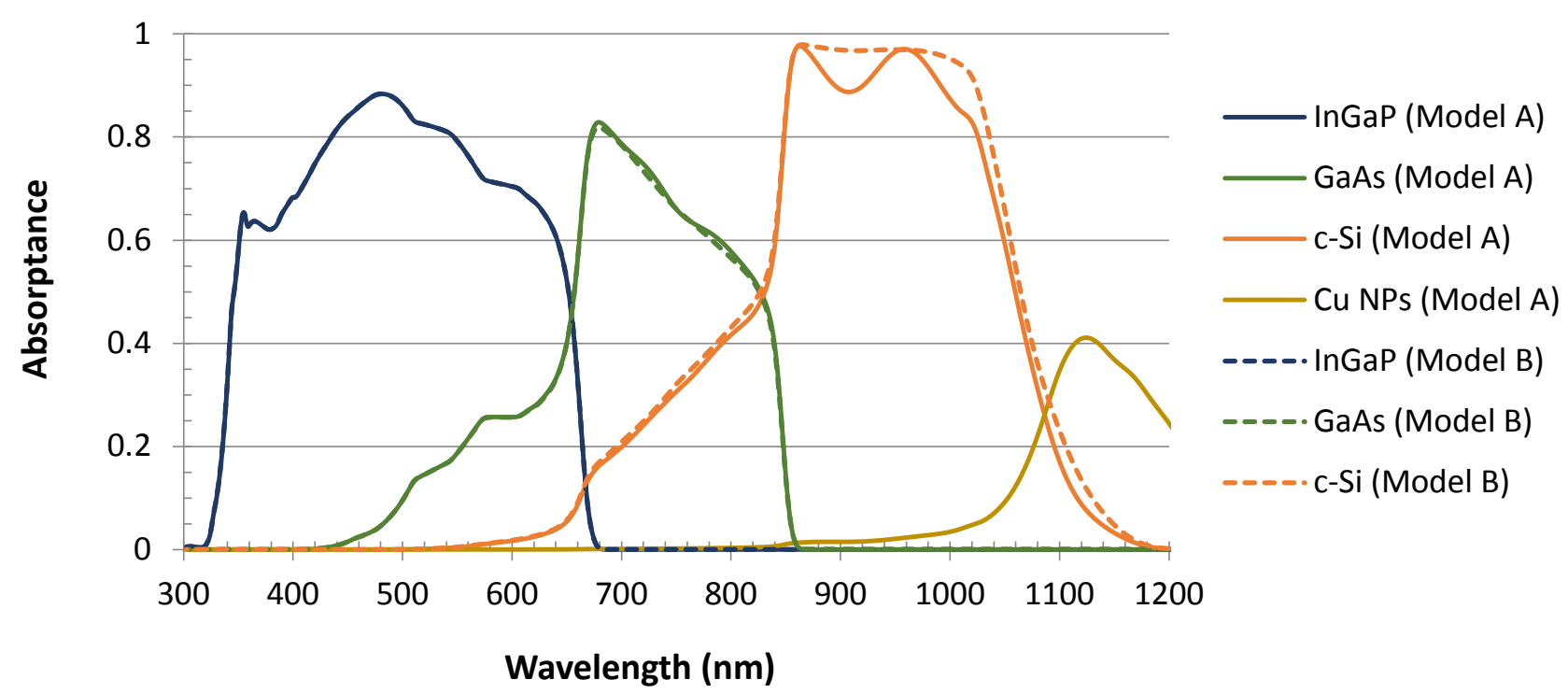

Figure S4. RCWA-simulated absorptance spectra of Model A and Model B.

\section{References}

[3] Schubert, M.; Gottschalch, V.; Herzinger, C. M.; Yao, H.; Snyder, P. G.; Woollam, J. A., Optical constants of Gaxln1-xP lattice matched to GaAs. Journal of Applied Physics 1995, 77, 3416.

[4] Aspnes, D. E.; Kelso, S. M.; Logan, R. A.; Bhat, R., Optical properties of AlxGa1-x As. Journal of Applied Physics 1986, 60, 754.

[5] Schinke, C.; Christian Peest, P.; Schmidt, J.; Brendel, R.; Bothe, K.; Vogt, M. R.; Kröger, I.; Winter, S.; Schirmacher, A.; Lim, S.; Nguyen, H. T.; MacDonald, D., Uncertainty analysis for the coefficient of band-to-band absorption of crystalline silicon. AIP Advances 2015, 5, 067168. 


\section{XPS spectrum of the Cu NPs}

The high-resolution XPS spectrum of the Cu NP array ( $C u 2 p$ region) formed on an oxide-free Si surface is shown below. The binding energy of the $2 p_{3 / 2}$ signal was $\sim 932.7 \mathrm{eV}$, which agreed well with the value expected for $\mathrm{Cu}^{0}$ (orange dashed line). ${ }^{6}$

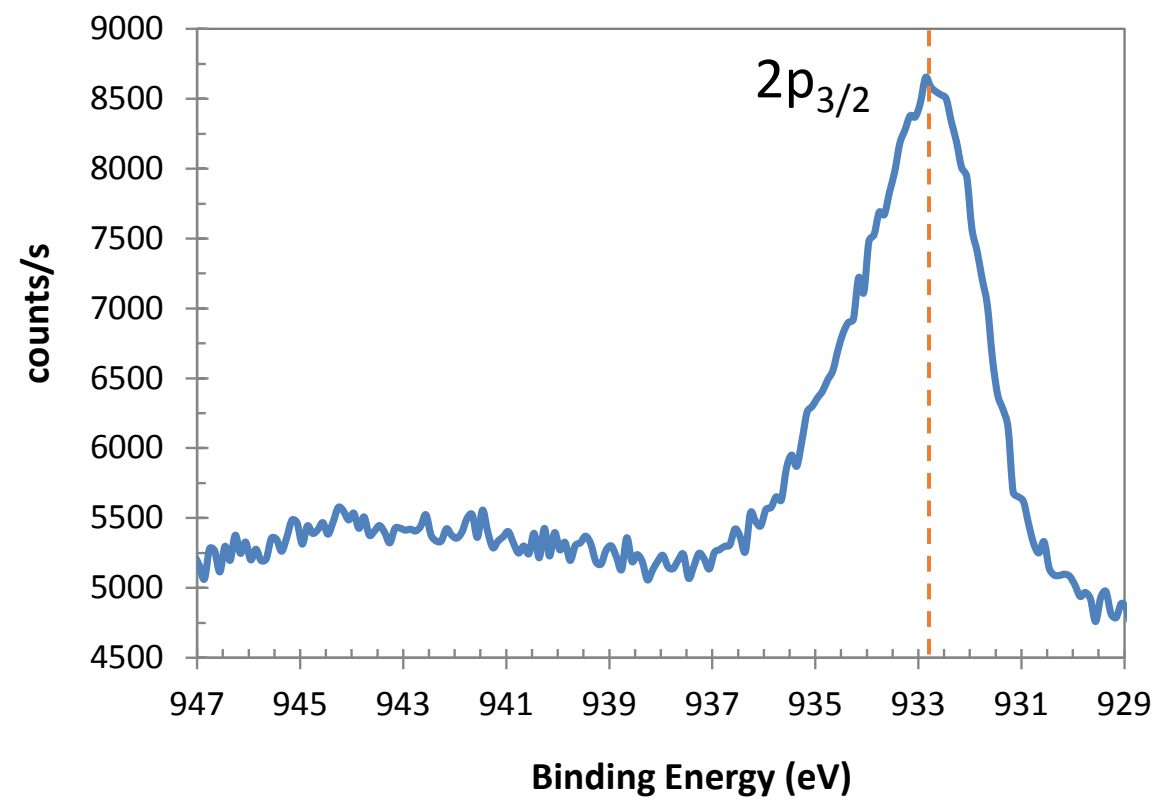

Figure S5. High-resolution XPS spectrum of the Cu NP array.

\section{Reference}

[6] Naumkin, A. V.; Kraut-Vass, A.; Gaarenstroom, S. W.; Powell, C. J. NIST X-ray Photoelectron Spectroscopy Database, Version 4.1, 2012. 